\title{
UHPLC-ESI-MS/MS analyses for quantification of phenolic compounds of Nepeta nuda subsp. Lydiae
}

\author{
Abdulmelik Aras ${ }^{1}$, Ercan Bursal $^{2 *}$, Mehmet Dogru ${ }^{1}$ \\ ${ }^{1}$ Department of Chemistry, Graduate School of Natural and Applied Sciences, Dicle University, Diyarbakır, Turkey. \\ ${ }^{2}$ Department of Nursing, School of Healths, Muş Alparslan University, Muş, 49100, Turkey.
}

\begin{tabular}{|c|c|}
\hline ARTICLE INFO & ABSTRACT \\
\hline Article history: & \multirow{7}{*}{$\begin{array}{l}\text { Phenolic compounds of Nepeta nuda subsp. Lydiae leaves were identified by UHPLC-ESI-MS/MS. To the best } \\
\text { of our knowledge, phenolic compounds in } N \text {. nuda subsp. Lydiae are reported for the first time. Chlorogenic } \\
\text { acid, rosmarinic acid and quinic acid, were found to be the most abundant compound in the methanol extract of } \\
N \text {. nuda subsp. Lydiae, among the twenty-seven compounds studied by LC-MS/MS. Also, smaller amounts of } \\
\text { kaempferol, p-coumaric acid, tr-caffeic acid, apigenin, luteolin and rhamnetin were identified, quantitatively. In } \\
\text { conclusion, leaves of } N \text {. nuda subsp. Lydiae have high potential of phenolic contents that mainly attributed with } \\
\text { biological activities. }\end{array}$} \\
\hline Received on: 07/09/2016 & \\
\hline Revised on: 08/10/2016 & \\
\hline Accepted on: 02/11/2016 & \\
\hline Available online: 29/11/2016 & \\
\hline Key words: & \\
\hline $\begin{array}{l}\text { Nepeta nuda, phenolic acid, } \\
\text { chlorogenic acid, rosmarinic } \\
\text { acid, quinic acid. }\end{array}$ & \\
\hline
\end{tabular}

\section{INTRODUCTION}

The genus Nepeta L. (Lamiaceae), herbaceous perennials, rarely annual, and often pleasantly aromatic herbs; stems erect or procumbent, eglandular or glandular, found in temperate Asia, Europe, North Africa, in mountains of tropical Africa and include about 250 species in the world (Davis, 1982; Ozhatay et al., 2009). Several Nepeta species are used in folk medicine as diuretic, diaphoretic, antitussive, antispasmodic, antiasthmatic, febrifuge, emmenagogue, and sedative agents; furthermore, many of these species are often pleasantly aromatic, rich in essential oils, and of potential economic interest (Tzakou et al., 2000; Rapisarda et al., 2001). N. nuda subsp. Lydiae is varies from other subspecies in terms of some characters; flower colour, stem indumentum, inflorescence and calyx characters (Davis, 1982). Phenolic compounds are secondary metabolites that widely existed throughout the plants, are known to have antioxidant properties. Phenolic compounds play important roles in neutralizing free radicals as well as to prevent lipid

* Corresponding Author

E-mail: ercanbursal @ gmail.com peroxidation chain reactions (Pacifico et al., 2015). Liquid chromatography with various detection techniques has been widely used to determine phenolic acids. Because of the high sensitivity and selectivity, HPLC coupled to ESI-MS has received considerable attention for the determination of phenolic acids (Yang et al., 2016). Thus, we aimed to determine the phenolic contents of $N$. nuda subsp. Lydiae by using UHPLC-ESI-MS/MS technique. According to the results, chlorogenic acid (1325 \pm 65 ppb), rosmarinic acid (238 $\pm 12 \mathrm{ppb})$ and quinic acid (224 \pm 11 $\mathrm{ppb}$ ) were identified as the major phenolic compounds.

\section{MATERIALS AND METHODS}

\section{Plant material}

The plant material was collected by Dr. Omer Kilic from a quercus forest $(1600-1700 \mathrm{~m})$ in Bingol, a southeast city of Turkey. The voucher specimens are deposited at the Department of Biology, Hacettepe University and at the Department of Park and Garden Plants of Bingol University, Turkey. The identification of plant sample was made by Dr. Kilic, according to volume 7 of Flora of Turkey (Davis, 1982). The leaves of plant were dried in air and collected until used. 


\section{Chemicals}

Standard phenolic compounds of LC-MS/MS (quinic acid, malic acid, tr-aconitic acid, gallic acid, chlorogenic acid, protocatechuic acid, tannic acid, tr- caffeic acid, vanillin, pcoumaric acid, rosmarinic acid, rutin, hesperidin, hyperoside, 4$\mathrm{OH}$ benzoic acid, salicylic acid, myricetin, fisetin, coumarin, quercetin, naringenin, hesperetin, luteolin, kaempferol, apigenin, rhamnetin, chrysin) were purchased from Sigma-Aldrich (Germany) and Fluka (Germany). The other chemicals were purchased from Sigma-Aldrich (Germany).

\section{Preparation of plant extract for LC-MS/MS}

The air-dried and powdered plant materials (100 g) were extracted three times with $300 \mathrm{~mL}$ of methanol for $24 \mathrm{~h}$ at room temperature. The solvent was removed under vacuum at $30^{\circ} \mathrm{C}$ in a rotary evaporator until dry methanol extracts were obtained (Yield:15.6\%). Dry filtrates were diluted to $1000 \mathrm{mg}$ extract/L and filtrated with $0.2 \mu \mathrm{m}$ microfiber filter prior to LC-MS/MS analysis.

\section{LC-MS/MS instrumentation and chromatographic conditions}

LC-MS/MS analyzes of the phenolic compounds were performed by using a Nexera model Shimadzu UHPLC coupled to a tandem MS instrument. The liquid chromatography was equipped with LC-30AD binary pumps, DGU-20A3R degasser, CTO-10ASvp column oven and SIL-30AC auto sampler. The chromatographic separation was performed on a C18 reversedphase Inertsil ODS-4 $(150 \mathrm{~mm} \times 4.6 \mathrm{~mm}, 3 \mu \mathrm{m})$ analytical column.

The column temperature was fixed at $40^{\circ} \mathrm{C}$. The elution gradient consisted of mobile phase A (water, $5 \mathrm{mM}$ ammonium formate and $0.1 \%$ formic acid) and mobile phase B (methanol, $5 \mathrm{mM}$ ammonium formate and $0.1 \%$ formic acid). The gradient program with the following proportions of solvent B was applied $\mathrm{t}$ (min), B\%: (0, 40), (20, 90), (23.99, 90), (24, 40), (29, 40). The solvent flow rate was maintained at $0.5 \mathrm{~mL} / \mathrm{min}$ and injection volume was settled as $4 \mu \mathrm{L}$.

\section{MS instrumentation}

MS detection was performed using Shimadzu LCMS 8040 model triple quadrupole mass spectrometer equipped with an ESI source operating in both positive and negative ionization modes. LC-MS/MS data were collected and processed by Lab Solutions software (Shimadzu, Kyoto, Japan).

The multiple reaction monitoring (MRM) mode was used to quantify the analytes: the assay of investigated compounds was performed following two or three transitions per compound, the first one for quantitative purposes and the second and/or the third one for confirmation. The optimum ESI conditions were determined as $\mathrm{DL}$ temperature; $250^{\circ} \mathrm{C}$, heat block temperature; $400^{\circ} \mathrm{C}$, nebulizing gas flow (nitrogen); $3 \mathrm{~L} / \mathrm{min}$ and drying gas flow (nitrogen); $15 \mathrm{~L} / \mathrm{min}$ (Ertas et al., 2015).

\section{RESULTS AND DISCUSSION}

Phenolic compounds contain one or more hydroxyl group with an aromatic structure and they exist in different species of plants. The phenolic compounds have antioxidant activities because of their redox properties, which allow them to act as reducing agents, hydrogen donors and quenchers of singlet oxygen (Turan et al., 2016; Is1k et al., 2015). Also, the structure of aromatic ring and the number of hydroxyl groups of phenolic compounds are important factors on antioxidant abilities. Phenolic compounds can interrupt chain oxidation reactions by donation of a hydrogen atom or chelating metals. Therefore identification and quantification of phenols from different source is increasingly becoming important due to their antioxidant potential. It was reported that compounds with structures containing functional hydroxyl groups can show metal chelation activity (Fiorucci et al., 2007). It was indicated that many phenolic compounds such as; curcumin, L-adrenaline, L-carnitine and quercetin bounded ferrous ions $\left(\mathrm{Fe}^{2+}\right)$ through groups and chelated metal ions (Gulcin 2012). Many methods such as; spectrophotometric, chromatographic and enzymatic methods have been used for determination of the phenolic acids of plants or foods. Liquid chromatography with various detection techniques has been widely used to determine phenolic acids. Because of the high sensitivity and selectivity, liquid chromatography coupled to ESI-MS has received considerable attention for the determination of phenolic acids (Sandin-Espana et al., 2016). In this study, we identified the phenolic acids of $N$. nuda subsp. Lydiae by UHPLC-ESI-MS/MS. We prefered to use methanol extract of $N$. nuda subsp. Lydiae for this purpose because it was previously stated that methanol has a protective role and prevents phenols from artificial oxidation by enzymes such as phenoloxidase.

The datas of phenolic compounds were shown on Table 1 as well as the UHPLC-ESI-MS/MS chromatograms of standards and plant extract were shown in Fig. 1A and Fig. 1B, respectively. According to the analysis of UHPLC-MS/MS, some chromatograms of plant extract were detected; peak 1 exhibited a negative molecular ion at $[\mathrm{MS}-\mathrm{H}]+$ at $\mathrm{m} / \mathrm{z}$ of 190.95 corresponding to quinic acid, the peak 5 has shown an $\mathrm{m} / \mathrm{z}$ of 353 which is the indication of chlorogenic acid, the peak 8 has shown an $\mathrm{m} / \mathrm{z}$ of 178.95 corresponding to tr-caffeic acid, the peak 10 has shown an $\mathrm{m} / \mathrm{z}$ of 136.95 corresponding to p-coumaric acid, the peak 11 has shown an $\mathrm{m} / \mathrm{z}$ of 151.05 corresponding to rosmarinic acid, the peaks 23,24 have shown $\mathrm{m} / \mathrm{z}$ of 284.95 corresponding to luteolin and kaempferol, the peak 25 has shown an $\mathrm{m} / \mathrm{z}$ of 268.95 corresponding to apigenin, the peak 26 has shown an $\mathrm{m} / \mathrm{z}$ of 314.95 corresponding to rhamnetin.

In order to establish the relationship between peak area and concentration, linear regression analysis was made for investigated standards. The ranges of calibration curves were 250$10000 \mu \mathrm{g} / \mathrm{mL}$ for quinic acid, malic acid, tr-aconitic acid, chlorogenic acid, vanillin, rosmarinic acid, rutin; 25-1000 $\mu \mathrm{g} / \mathrm{mL}$ for gallic acid, tr-caffeic acid, 4-OH benzoic acid, salicylic acid, quercetin, naringenin, hesperetin, luteolin, kaempferol, apigenin, 

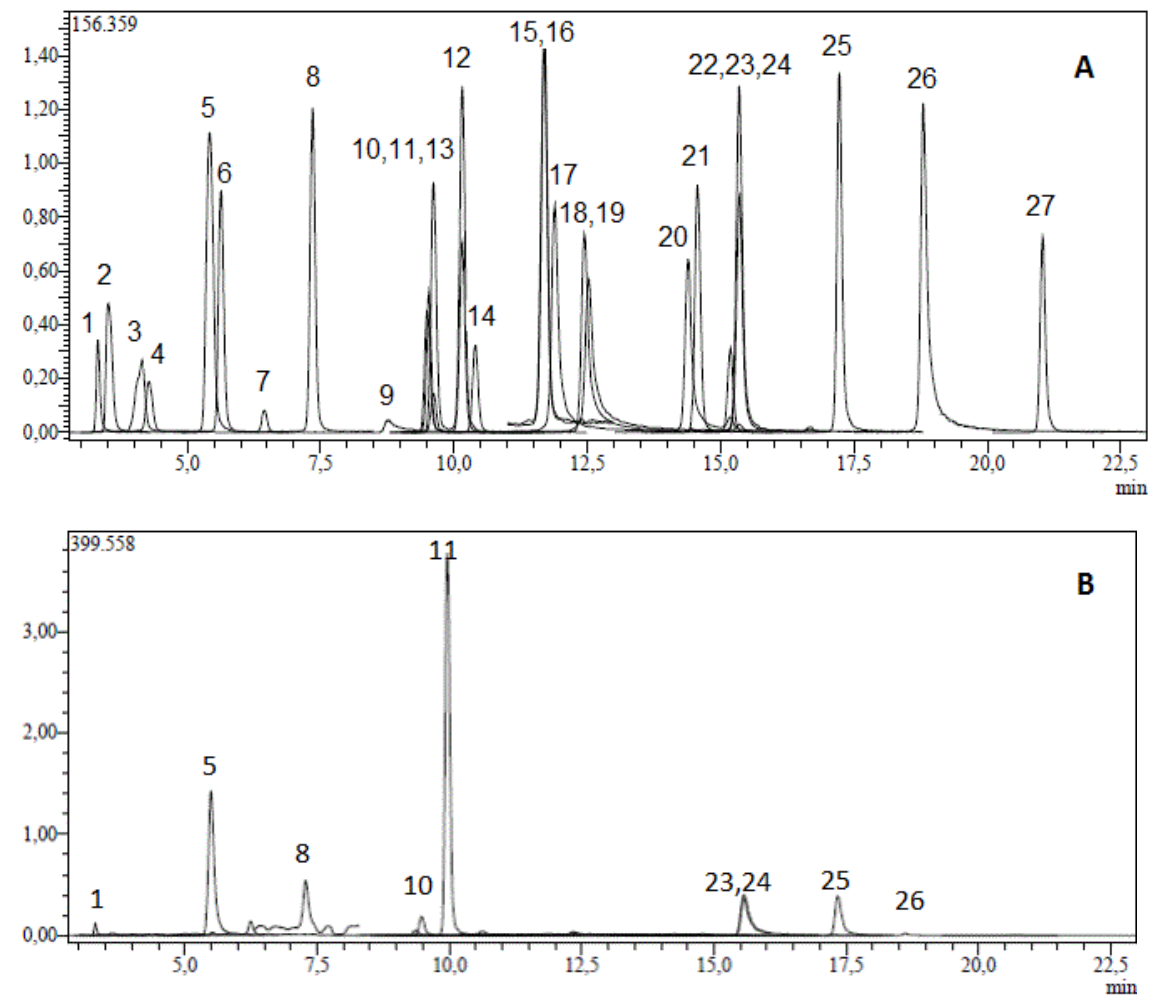

Fig. 1: UHPLC-ESI-MS/MS chromatograms of standard phenolic compounds (A) and methanol extract of $N$. nuda subsp. Lydiae (B); (1:quinic acid, 2:malic acid, 3:tr-aconitic acid, $\mathbf{4}$ :gallic acid, 5:chlorogenic acid, 6:protocatechuic acid, 7 :tannic acid, $\mathbf{8}$ :tr- caffeicacid, 9:vanillin, 10:p-coumaric acid, 11:rosmarinic acid, 12:rutin, 13:hesperidin, 14:hyperoside, 15:4-OH benzoic acid, 16:salicylic acid, 17:myricetin, 18:fisetin, 19:coumarin, 20:quercetin, 21:naringenin, 22:hesperetin, 23:luteolin, 24:kaempferol, 25:apigenin, 26:rhamnetin, 27:chrysin).

rhamnetin, chrysin and $100-4000 \mu \mathrm{g} / \mathrm{mL}$ for protocatechuic acid, tannic acid, p-coumaric acid, hyperoside, fisetin, coumarin.

The linearity was estimated via linear regression analysis and expressed as correlation coefficient (R). The result showed that the peak area is strongly related to concentration (Table 1). Correlation coefficient $(\mathrm{R})$ was higher than 0.99 for all standard except for hyperoside $(\mathrm{R}=0.95)$. We also calculated LOD and LOQs which are ranged 0.05-25.8 and 0.17-74.5, respectively. To quantify each phenolic compound in the sample, the individual peak areas of each component from UHPLC-MS/MS chromatogram profile were compared with the areas of standards at known concentrations. The amount of each compound was expressed as $\mu \mathrm{g}$ analyte $/ \mathrm{kg}$ (ppb) dried plant material.

According to the results; chlorogenic acid $(1325 \pm 65$ ppb), rosmarinic acid (238 $\pm 12 \mathrm{ppb})$ and quinic acid (224 \pm 11 $\mathrm{ppb}$ ) were detected as major phenolic compounds as well as smaller amounts of kaempferol ( $89 \pm 5 \mathrm{ppb})$, p-coumaric acid ( 86 $\pm 4 \mathrm{ppb}$ ), tr-caffeic acid (73 $\pm 4 \mathrm{ppb})$, apigenin (56 $\pm 3 \mathrm{ppb})$, luteolin $(19 \pm 1 \mathrm{ppb})$, and rhamnetin $(9 \pm 1 \mathrm{ppb})$ identified, quantitatively (Table 1). Chlorogenic acid, rosmarinic acid and quinic acid were detected as main phenolics from N. nuda subsp. Lydiae by UHPLC-ESI-MS/MS method. These phenolic compounds contain hydroxyl groups which have significiant roles on biological properties. Biological activities of phenolic compounds usually depend on not only the numbers of hydroxyl groups but also the positions of the hydroxyl groups and presence of other functional groups (Bursal, 2013). Chlorogenic acid is a natural dietary flavanone which has been identified in different species of plants. Chlorogenic acid has been recognized as a potent antioxidant, antinflammatory and anticarcinogenic agent. In a previous report, high amounts of chlorogenic acids were estimated by the chromatography analysis from green coffee beans. Also, high antioxidant capacities of different coffee brews determined by Folin-Ciocalteu, ABTS and DPPH in vitro assays (JeszkaSkowron et al., 2016). So, it could be a relation between concentration of chlorogenic acid and antioxidant capacity. Rosmarinic acid is a natural polyphenolic acid, an ester of caffeic and 3,4-dihydroxyphenyllactic acids. Rosmarinic acid was isolated and identified as one of the main component of several medicinal plants. It was reported that rosmarinic acid had several biological activities, namely antioxidant, anti-inflammatory, antibacterial, antiviral, antitumor, hepatoprotective and cardioprotective properties (Petersena and Simmonds, 2003). In a previous study, it was reported that the a methanol extract of Thymus nummularius contained high amounts of rosmarinic acid and it had a very rich phenolic content (Ertas et al., 2015). Quinic acid is obtained from cinchona bark, coffee beans, and other plant products. It is a constituent of tannins. It was reported that quinic acid had been found on the extract of Caesalpina spinosa (Garro Galvez et al., 1997). 
<smiles>O=C(/C=C/c1ccc(O)c(O)c1)OC1CC(O)(C(=O)O)C[C@H](O)[C@@H]1O</smiles><smiles>O=C(/C=C/c1ccc(O)c(O)c1)O[C@H](Cc1ccc(O)c(O)c1)C(=O)O</smiles><smiles>O=C(O)[C@]1(O)C[C@@H](O)[C@H](O)C[C@H]1O</smiles>

Fig. 2: Chemical structure of main phenolics from N. nuda subsp. Lydiae; a) chlorogenic acid, b) rosmarinic acid, c) quinic acid

Table 1: LC-MS/MS parameters of selected compounds and amount of $N$. nuda subsp. Lydiae.

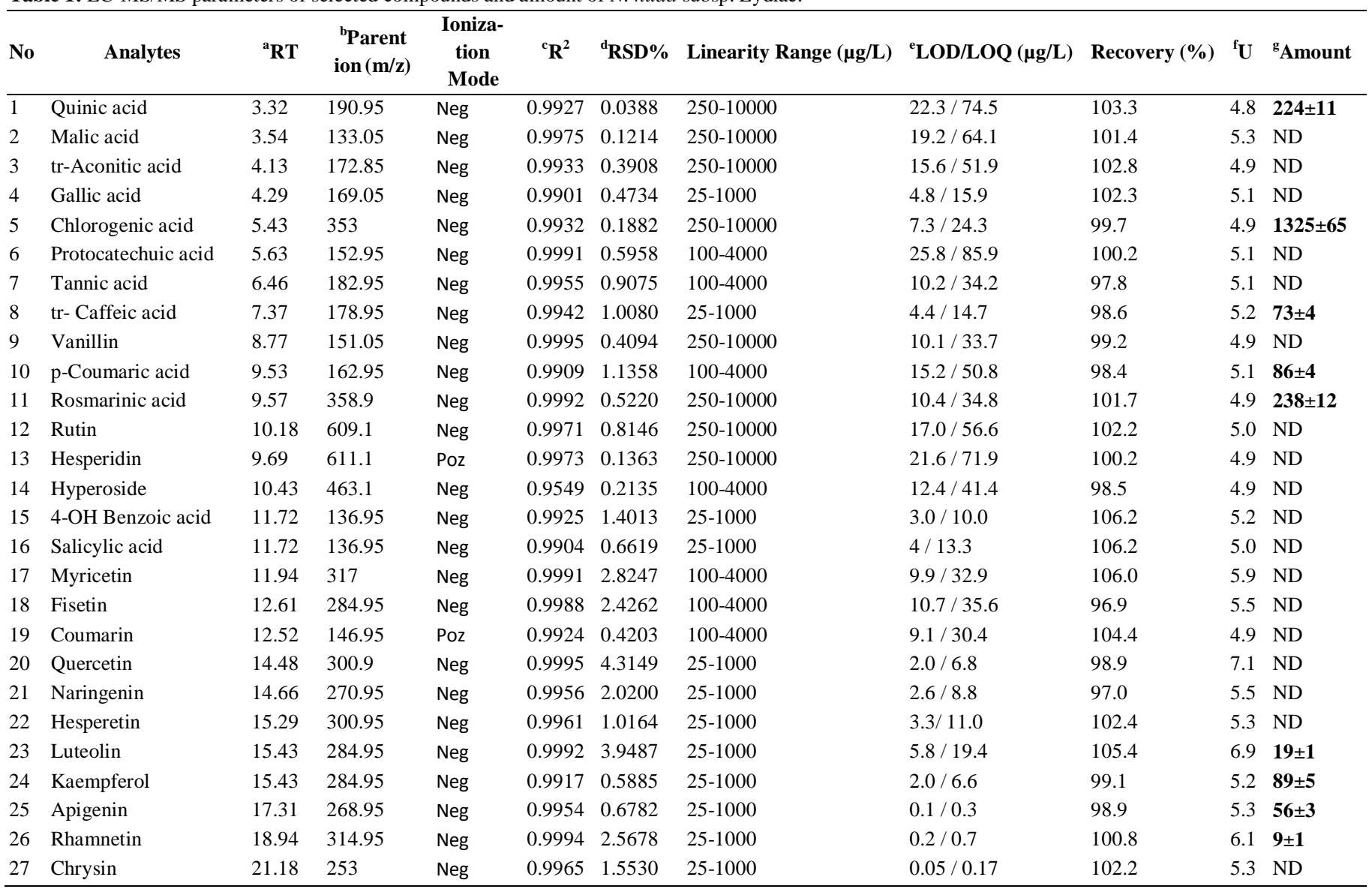

${ }^{\mathbf{a}}$ : Retention time, ${ }^{\mathbf{b}}$ : Molecular ions of the standard compounds (mass to charge ratio), ${ }^{\mathbf{c}}$ : Coefficient of determination, ${ }^{\mathbf{d}}$ : Relative standard deviation, ${ }^{\mathbf{e}}$ : Limit of detection/Limit of quantification, ${ }^{\mathrm{f}}:$ Percent relative uncertainty at $95 \%$ confidence level $(\mathrm{k}=2),{ }^{\mathrm{g}}$ : Quantitative results of real samples in $\mu \mathrm{g}$ analyte/kg (ppb). 


\section{CONCLUSION}

The phenolic composition of $N$. nuda subsp. Lydiae was investigated by UHPLC-ESI-MS/MS analyses. Chlorogenic acid, rosmarinic acid and quinic acid are found to be the highest amounts of phenolic acids. The effective biological activities of $N$. nuda subsp. Lydiae might be due to its rich amounts of phenolic compounds. As a result, leaves of $N$. nuda subsp. Lydiae have high potential to be used in food industry and pharmaceutical industry.

\section{ACKNOWLEDGMENT}

We would like thank to Dr. Omer Kilic for supplying and identification of plant sample.

Financial support and sponsorship: We gratefully acknowledge financial support from the Dicle University (ZGEF.15.002).

Conflict of Interests: There are no conflicts of interest.

\section{REFERENCES}

Bursal E. Kinetic properties of peroxidase enzyme from chard (Beta vulgaris subspecies cicla). Int. J. Food Prop, 2013; 16(6): 1293 1303.

Davis PH. 1982. Flora of Turkey and the East Aegean Islands 7, Edinburgh University Press, Edinburgh.

Ertas A, Boga M, Yilmaz MA, Yesil Y, Tel G, Temel H, Hasimi N, Gazioglu I, Ozturk M, Ugurlu P. A detailed study on the chemical and biological profiles of essential oil and methanol extract of Thymus nummularius (Anzer tea): Rosmarinic acid. Ind. Crop. Prod, 2015; 67: 336-345

Fiorucci SB, Golebiowski J, Cabrol-Bass D, Antonczak S. DFT study of quercetin activated forms involved in antiradical, antioxidant, and prooxidant biological processes. J. Agric. Food Chem, 2007; 55: 903-911.

Garro Galvez JM, Ried B, Conner AH. Analytical studies on tara tannins. Holzforschung, 1997; 235-243.

Gulcin I. Antioxidant activity of food constituents-An overview. Archives of Toxicology, 2012; 86: 345-396.

Isık M, Korkmaz M, Bursal E, Gulcin I, Koksal E, Tohma H. Determination of antioxidant properties of Gypsophila bitlisensis bark. Int. J. Pharm, 2015; 11(4): 366-371.
Jeszka-Skowron M, Stanisz E, De Pena MP. Relationship between antioxidant capacity, chlorogenic acids and elemental composition of green coffee. LWT-Food Science and Technology, 2016; 73: $243-250$

Ozhatay N, Kultur S, Aslan S. Check-list of additional taxa to the supp. Flora of Turkey IV. Turk. J. Bot, 2009; 33: 191-226.

Pacifico S, Galasso S, Piccolella S, Kretschmer N, Pan SP, Marciano S, Bauer R, Monaco P. Seasonal variation in phenolic composition and antioxidant and anti-inflammatory activities of Calamintha nepeta (L.) Savi. Food Res. Int, 2015; 69: 121-132.

Petersena M, Simmonds MSJ. Rosmarinic acid. Phytochemistry, 2003; 62: 121-125.

Rapisarda A, Galati EM, Tzakou O, Flores M, Miceli N. Nepeta sibthorpii Betham (Lamiaceae): Micromorphological analysis of leaves and flowers. Farmaco, 2001; 56: 413-415.

Sandin-Espana P, Mateo-Miranda M, Lopez-Goti C, De Cal A, Alonso-Prados JL. Development of a rapid and direct method for the determination of organic acids in peach fruit using LC-ESI-MS. Food Chem, 2016; 192: 268-273.

Turan N, Adiguzel R, Buldurun K, Bursal E. Spectroscopic, thermal and antioxidant properties of novel mixed ligand-metal complexes obtained from saccharinate complexes and azo dye ligand (mnppa). Int. J. Pharm, 2016; 12(2): 92-100.

Tzakou O, Haruda C, Galati EM, Sanogo R. Essential oil composition of Nepeta argolica Bory et Chaub. subsp. argolica. Flavour Fragr J, 2000; 115-118.

Yang B, Feng X, Xu J, Lei H, Zhang L. Multi-component HPLC analysis and antioxidant activity characterization of extracts from Dipsacus sativus (Linn.) Honck. Int. J. Food Prop, 2016; 19(5): 1000-1006

\section{How to cite this article:}

Aras A, Bursal E, Dogru M. UHPLC-ESI-MS/MS analyses for quantification of phenolic compounds of Nepeta nuda subsp. Lydiae. J App Pharm Sci, 2016; 6 (11): 009-013. 